\title{
ULTRAVIOLET TRANSMISSION CHANGES IN GLASS AS A FUNCTION OF THE WAVE LENGTH OF THE RADIATION STIMULUS
}

\author{
By W. W. Coblentz and R. Stair
}

\section{ABSTRACT}

Continuing the research previously reported in Research Paper 113 further consideration is given to methods of testing the photochemical stability of window glass made for transmitting short wave length ultraviolet solar radiation. It is shown that accelerating the stabilization of the transmission of window glass (equivalent to the stabilization produced by sunlight) by means of filtered ultraviolet radiation from the quartz mercury arc is impracticable principally because of the antagonistic action of radiation of wave lengths in the region of about $365 \mathrm{~m} \mu$ which reverses, in varying degrees, the photochemical reaction produced by the shorter wave lengths.

A new phenomenon in the ultraviolet transmission behavior of certain glass is reported. The phenomenon may be briefly described as follows: When irradiated with light of a given wave length (in the region 250 to $365 \mathrm{~m} \mu$ ) the sample of glass reaches an equilibrium state in which the transmission (at $302 \mathrm{~m} \mu$, for example,) attains a certain value, which is a constant for the given wave length stimulus. The equilibrium value of the transmission is different for each wave length of the radiation stimulus, increases with increasing wave length of the stimulus, and is independent of the previous order of treatment of the glass.

In place of a chemical analysis, the absorption spectrum (which is a characteristic of every chemical compound), is used as a criterion for judging the magnitude of photochemical action produced by ultraviolet radiation of different wave lengths of homogeneous radiation.

In the soda-lime-silica glasses examined (whether or not they contained an appreciable amount of iron oxide) the photochemical equilibrium was found to be different for each wave length of homogeneous radiation to which the glass reacts. To attain this equilibrium the reaction, caused by a given wave length, is in the direction to either increase or decrease the transmission, depending upon the existing condition developed by previous heat treatment or by previous exposure to other wave lengths to which the glass reacts.

Using homogeneous radiation, no wave length (at least not for wave lengths shorter than and including $365 \mathrm{~m} \mu$ ) was found that has the exclusive property of either increasing or decreasing the ultraviolet transmission in the soda-lime-silica glasses examined.

The longest wave length having an appreciable photochemical action on a soda-lime-silica glass is at about $405 \mathrm{~m} \mu$. For wave lengths $365 \mathrm{~m} \mu$ and shorter, the photochemical action as determined by the equilibrium levels in spectral absorption, is a function of the wave length (the frequency) of the radiation stimulus; the shorter the wave length the greater the photochemical action in the direction of greater absorption.

In contrast with a soda-lime-silica glass, a phosphate-lime glass (containing oxides of $\mathrm{Al}, \mathrm{B}, \mathrm{Na}, \mathrm{Mg}, \mathrm{Si}$, and $\mathrm{Fe}$ as minor constituents) is depreciated in ultraviolet transmission only by wave lengths shorter than about $290 \mathrm{~m} \mu$. After depreciation, the ultraviolet spectral transmission curve of the calcium phosphate glass is similar to that of a soda-lime-silica glass. Nevertheless, exposure of the depreciated calcium-phosphate glass to homogeneous radiation of wave lengths 297 to $365 \mathrm{~m} \mu$ does not appreciate the transmission, as is the case in the sodalime-silica glass. In other words, in contrast with the soda-lime-silica glass, certain wave lengths have the property of decreasing the ultraviolet transmission; but in the spectral range investigated no reverse reaction was observed. 
I. Introduction

II. Experimental procedure

III. Experimental data

1. Seasonal variation in transmission of special window glasses

2. Effect of heterogeneous ultraviolet radiation upon the transmission of glass _.

(a) Series I

(b) Series II

(c) Series III.

3. Effect of homogeneous ultraviolet radiation upon the transmission of glass . .

(a) Effect upon a soda-lime-silica glass

(b) Effect upon a phosphate-lime glass

4. Spontaneous recovery in transmission

IV. Discussion of data

1. Photochemical equilibrium states

(a) A soda-lime silica glass

(b) A phosphate-lime glass

2. Relation between the transmission and the integrated energy absorbed..... 794

V. References and notes

\section{INTRODUCTION}

The object of the present paper is twofold: (a) to describe the results of studies of the depreciation and appreciation (the so-called "solarization and rejuvenation") of the ultraviolet transmission of window glasses, by exposure to filtered and unfiltered heterogeneous radiation from the sun, and from the quartz mercury arc, and (b) to describe some preliminary results of similar studies of photochemical changes in glass produced by isolated wave lengths of homogeneous radiation from the quartz mercury arc.

The information derived from the first study (a) is of commercial importance in connection with methods of testing the photochemical stability, by accelerating the aging of special window glass made for transmitting short wave length ultraviolet solar radiation shut out by common window glass.

The information derived from the second study (b), which has resulted in the discovery of a new phenomenon in the ultraviolet transmission behavior of certain glasses, is of importance in connection with the question of the "antagonistic" action of different wave lengths in photochemical reactions, and may perhaps contribute to the elucidation of claims of antagonistic action of different wave lengths in certain biological reactions, particularly supposed changes in the constituents of the blood (hemoglobin).

Although the literature contains numerous papers $(9)^{1}$ on the so-called "antagonistic photochemical and photographic effects of different wave lengths of thermal radiation", but little information seems available on the reversibility (2) (3) of a photochemical reaction that occurs in certain window glasses (incidentally containing a small amount of iron oxide as an impurity) when exposed to heterogeneous radiation of different wave lengths. In fact, the herein described experiments appear to disclose an entirely new phenomenon, namely, the reversibility of a photochemical reaction in glass, the direction of the reaction caused by a single wave length of homogeneous radia-

1 Figures in parentheses here and throughout the text and footnotes indicate references and notes given at the end of this paper. 
tion depending upon the existing chemical condition developed in the glass as a result of previous exposure to radiation of other wave lengths. Whether this phenomenon is a result of the occurrence of more than one photochemical reaction remains undetermined (16).

It has been known for more than two decades that ferrous oxide in glass is more transparent to ultraviolet radiation than ferric oxide; and this observation is now the basis for making glasses to protect the eyes from injurious ultraviolet radiation by keeping the iron oxide in the ferric condition.

On the other hand, because of the low transparency of ferric oxide in the ultraviolet, the problem in the manufacture of special window glasses for transmitting short wave length ultraviolet solar radiation shut out by common window glass, is to procure raw materials that are as free as possible from iron.

Recently Starkie and Turner (13) made a quantitative investigation of soda-lime-silica glasses prepared from carefully selected materials containing a negligible amount of iron oxide. Small amounts of pure ferric oxide were progressively added to form a series of glasses containing from 0.005 to 1.0 percent (calculated) of iron oxide. Of the total iron in each sample 93 percent was in the ferric condition; and, in agreement with their expectations, these glasses (while being lower in initial transmission) did not depreciate in transmission on exposure to ultraviolet radiation.

On the other hand, in certain commercial glasses in which 31 to 48 percent of the total iron oxide present was in the ferrous condition before irradiation, the ultraviolet transmission decreased coincidently with the reconversion of ferrous into ferric oxide by irradiation, the ferrous oxide falling to about 20 percent of the total. At this stage the transmission had become relatively stable to the total ultraviolet radiation from the carbon arc lamp.

Starkie and Turner (13) cite experiments by Sugie (21) showing that in a soda-lime-silica glass the ferric oxide lowered the ultraviolet transmission more than the ferrous oxide; whereas in a potash-limesilica glass there was no difference between the two forms (23).

It has been found recently (2) (3) that the stability of the transmission of the glass is a relative term, depending upon the wave length of the activating radiation.

The present research shows the readiness with which the photochemical reaction in a soda-lime-silica glass made from pure materials (also samples containing iron oxide as an impurity, and, in some cases, containing oxides of As or Mn as a decolorizer) is reversed by merely changing the wave length of the exciting radiation. It shows also the facility with which the reversibility of this reaction can be studied qualitatively by physical methods (that is, by spectral ultraviolet radiometry) even though we cannot, as yet, correlate the physical measurements with the photochemical products formed in the glass, as would be deduced by chemical analysis.

In previous reports (10), (11), data were given on the rejuvenation in transmission of glasses by heat treatment. But this, insofar as is known and, in contrast with the herein-described photochemical reaction (which appears to be an unusual phenomenon that deserves further investigation) is not in the same sense a reversible process. For this suggested investigation a glass should be used that is made of materials that are relatively nonphotosensitive in the spectral region 
under investigation; and also other glasses by using in addition varied amounts of supposedly photosensitive materials (e. g., oxides of sodium, arsenic, iron, manganese, phosphorus, etc., and also combinations of these materials). From an investigation of such glasses it should be possible to elucidate the herein-described equilibrium levels of photochemical stability for different wave lengths and for different materials.

From the foregoing citations it is to be noted that, heretofore, the transparency and photochemical stability of a window glass (a sodalime-silica glass) has been discussed with reference to the iron oxides present as an impurity, the ferrous oxide being assumedly changed into the ferric by the action of the ultraviolet rays. But no attempt seems to have been made to determine: (a) whether the photochemical instability is in the pure soda-lime-silica glass, or is a result of the presence of the iron oxides; (b) whether the oxide of iron changes from the ferrous to the ferric condition because of the oxygen set free in the main constituents; (c) whether the iron oxides act as catalyzers in increasing the photochemical reaction in the soda-lime-silica constituents; or (d) whether the photochemical reaction in the relatively iron-free soda-lime-silica glass is a result of the presence of dissolved $\mathrm{CO}_{2}$ or $\mathrm{H}_{2} \mathrm{O}$. The latter has a catalytic action in photolysis (20).

From the herein-described experiments on various special window glasses (10), some having a lower iron oxide content than others, and on a sample of soda-lime-silica glass, prepared from pure materials, ${ }^{2}$ it appears that a soda-lime-silica glass, practically free from iron, is photosensitive.

The present investigation is, therefore, being undertaken anew, using pure (iron-free) materials to determine the photochemical stability of oxides of $\mathrm{Na}, \mathrm{Ca}, \mathrm{K}, \mathrm{As}$, etc., in various glasses which, for purposes of comparison, are being prepared by different methods in different laboratories (23).

This Bureau's interest in the question of the solarization of special window glasses, marketed for transmitting short wave length (290 to $310 \mathrm{~m} \mu$ ) solar radiation shut out by common window glass, began in the spring of 1927, and in the following October a report was issued (1) stating that all these new window glasses decrease in transparency when exposed to the sun, to the carbon arc, and to the quartz mercury arc; and that the stabilized transmission depends in some undetermined manner upon the (ferrous and ferric) iron oxides present as an impurity.

It was found also, on exposure of the glass to the unfiltered radiation from a quartz mercury arc lamp (which emits radiation of wave lengths shorter than $290 \mathrm{~m} \mu$; not present in sunlight), that the ultraviolet transmission was reduced to a lower value than that obtained by exposure to the sun.

Subsequently it was found by Wood and Leathwood (2) and also by the writers (3) that exposure of the glass to sunlight, after exposure to the mercury arc lamp, restores the ultraviolet transmission close to the minimum value obtained by exposure only to the summer sun, thus explaining an earlier discrepancy in transmission measurements of the Bureau and the Smethwick, England, laboratories on a sample of irradiated glass that during the interchange between

2 Supplied by F. C. Flint of the Hazel Atlas Glass Co., in December 1928. Recently samples of pure (relatively iron-free) soda-lime-silica and soda-silica glasses, prepared by A. N. Finn of this Bureau, were found to be unstable photochemically. 
the two laboratories had undergone partial rejuvenation by exposure to daylight.

Moreover, when the exposure was made to the sun in the winter, i. e., when the wave lengths shorter than $305 \mathrm{~m} \mu$ were almost entirely absent, it was found by the writers that there was an apparent overshooting of the recovery in transmission (3) (4) which was not permanent. With the advancing spring season the transmission decreased again to a value that is closely the same as that attained by exposure only to the summer sun. As shown in the present paper, this was probably owing to the fact that the short wave length ultraviolet (less than $305 \mathrm{~m} \mu$ ), absent in winter sunlight, counteracts the rejuvenating action of the ultraviolet rays of wave lengths in the region of $365 \mathrm{~m} \mu .^{3}$

In order to demonstrate that this rejuvenation in transmission is selective as to wave length, samples of glass were first exposed to the unfiltered radiation from the quartz mercury-arc lamp (3) and then exposed to the same lamp through suitable glass filters. In the same manner duplicate samples were solarized by exposure to unfiltered sunlight and then reexposed to sunlight filtered through suitable screens (4) (5), as more fully described in the present paper.

This solarization and rejuvenation was carried through several cycles (5) (6), using solar radiation and quartz mercury arc radiation as sources. In both cases the results were conclusive in demonstrating that the wave lengths in the spectral range of $313 \mathrm{~m} \mu$ to $405 \mathrm{~m} \mu$ have the power of reversing the photochemical action produced by the shorter wave lengths.

Since the mercury arc spectrum is highly discontinuous, with but few emission lines in the region of 297 to $365 \mathrm{~m} \mu$, it is impossible to provide a filter for mercury arc solarization tests that will produce a spectral energy distribution similar to sunlight, although the photochemical action of such filtered radiation may perhaps be approximately the same as sunlight. Stockbarger's (8) data seem to show a similarity in the effect of sunlight and a filtered mercury-arc radiation. It will be noted, however, that his exposures to the sun were made during the months of January to March when, as will be shown presently, the solarization is not as effective as in summer sunlight. Consequently, as previously noted by the writers (6) (7), the stabilized transmission obtained by exposure of the glass to filtered radiation from the mercury arc may not be as low (depending upon the filter) as that obtained by exposure to direct summer sunlight, and hence the use of filtered radiation from the quartz mercury arc may be less reliable than unfiltered radiation in making stabilized transmission tests. Another objection to stabilizing the glass under a filter is the long exposures required.

The method of correlating the stabilized transmissions obtained on exposure to the mercury arc and sunlight, respectively, was given in a previous communication (3) in which it is shown that the great variations in transmission of different melts of the same kind of glass outweight the relatively small uncertainties in the accelerated stabilization of the transmission by using the unfiltered mercury-arc radiation. Moreover, the requirement of long exposures (some 200 hours) to filtered radiation (7) and of new filters for each new acceleration test (6) makes the filter method less practicable than the stabilization of

\footnotetext{
${ }^{3}$ While this is an interesting scientific observation, as already indicated (5), the actual amount of recovery in transmission of an ultraviolet window glass, during the winter, is not sufficient to warrant recognition in the sales promotion of window glasses that solarize on exposure to (summer) sunlight.
} 
the transmission by means of unfiltered radiation and adjustment of the value by a factor based on average values obtained from previous observations on samples of the same make of glass, stabilized by exposure to the lamp and to the sun (3).

\section{EXPERIMENTAL PROCEDURE}

In a previous paper (10) it was shown that whenever there is a change in the ultraviolet transmission of glass, either as the result of solarization by exposure to heterogeneous ultraviolet radiation, or of rejuvenation by heat treatment, this change is not confined to a narrow band of wave lengths, but extends from about $405 \mathrm{~m} \mu$ to an undetermined wave length shorter than $254 \mathrm{~m} \mu$. On a subsequent page it is shown that this same phenomenon occurs when the solarization and rejuvenation are produced by homogeneous radiation. That is to say, whatever the new substance (or substances) may be that is formed by photochemical action, its absorption spectrum is not confined to narrow bands (as for example, obtains in irradiated ergosterol) but extends over a wide region into the shortest ultraviolet (to an undetermined wave length) where it is submerged by the exceedingly high absorption of the main constituents of the glass.

Hence, in view of the impracticability of determining the complete spectral ultraviolet transmission curve after each irradiation of the glass, in the present as in the previous investigation (10), the transmission for the emission line of the quartz mercury arc, at the wave length $302 \mathrm{~m} \mu$, is used as an indicator of the photochemical change produced in the glass by irradiation.

For this purpose a spectroradiometer, consisting of two uncemented quartz-fluorite achromatic lenses, $33 \mathrm{~mm}$ in diameter and $30 \mathrm{~cm}$ focal length, and a quartz prism $6 \mathrm{~cm}$ in height, was used (15). This produced a long spectrum from which the emission line at $302 \mathrm{~m} \mu$ was easily isolated and the transmission of the glass, for this line, was measured by means of a previously described vacuum thermopile and ironclad Thomson galvanometer.

The source of ultraviolet for these transmission measurements was a vertical "Uviarc" quartz mercury-arc lamp, focused upon the spectrometer slit by means of an achromatic lens of quartz-fluorite. Since even a short exposure of these highly photosensitive glasses to the unfiltered radiation from this lamp produced an appreciable decrease in their transmission (if above the equilibrium level for the total radiation of the lamp), a plate of Corex-D glass (having a transmission of 50 percent at $302 \mathrm{~m} \mu$ and less than 1 percent at $280 \mathrm{~m} \mu$ ) was mounted in front of the arc, during the transmission measurements, at $302 \mathrm{~m} \mu$ and longer wave lengths. As a further precaution, in most cases when the transmission was above 25 percent at $302 \mathrm{~m} \mu$, a glass filter (having a transmission of 5 percent at this wave length) was used, and the value at $302 \mathrm{~m} \mu$ calculated from the observed transmission at $313 \mathrm{~m} \mu$. When the transmission was below 20 percent (at $302 \mathrm{~m} \mu$ ) no filter was used.

For investigating the photochemical action of homogeneous radiation, the above-mentioned vertical quartz mercury arc lamp was operated at a constant potential (70 volts). The single wave lengths were isolated by means of a high-powered quartz spectropyrheliometer, as used in previous investigations (14). The intensities of the lines at the exit slit were evaluated in absolute units. 
The sample to be irradiated with homogeneous radiation was securely attached to a suitable support which could be mounted in a fixed position directly back of this exit slit for irradiation purposes; and in a fixed position before the entrance slit of the quartz-fluorite spectrometer for transmission measurements. Since the width of the irradiated part of the sample was about $1 \mathrm{~mm}$, and the transmission measurements were made upon the central portion of this irradiated area, about $0.5 \mathrm{~mm}$ in width, there is practically no uncertainty in making the transmission measurements upon the central part of the irradiated area.

Most of the measurements using heterogeneous filtered radiation preceded the work with homogeneous radiation. In the preliminary search (3) (4) for the approximate wave-lengths of the exciting radiation (effective in producing solarization and rejuvenation of the

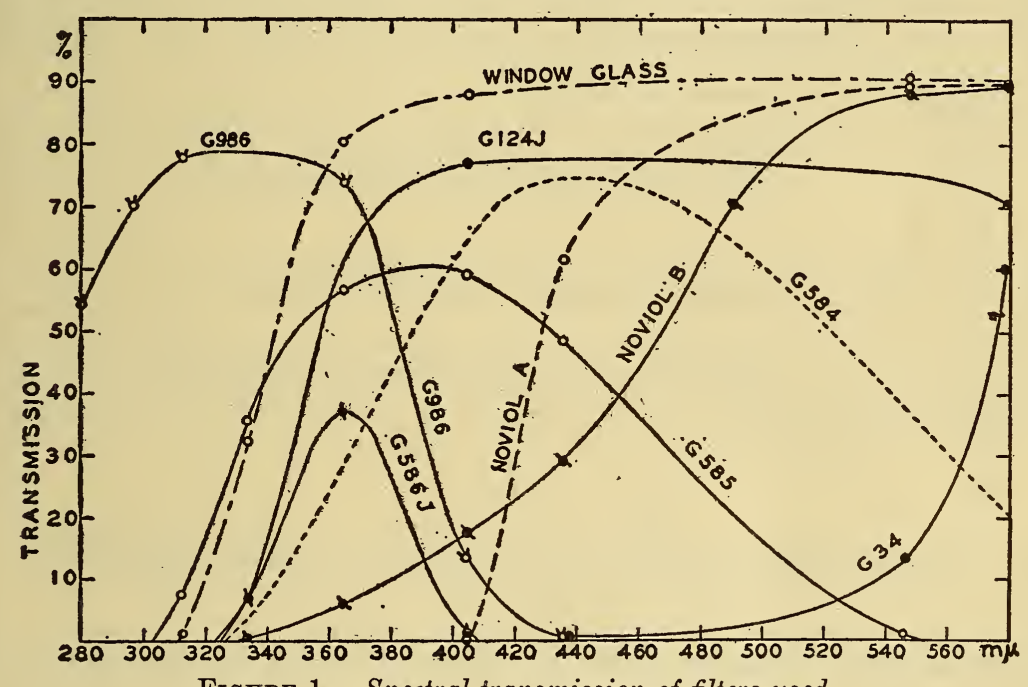

FIGURE 1.-Spectral transmission of filters used.

transmission of glasses), a series of nine filters, including red, yellow (Corning G34 and Noviol B), green (G584 and 585), violet (G586J and G986), and colorless window glass, was used to isolate wide spectral bands of solar and quariz mercury arc radiation. The spectral transmission curves of these filters are depicted in figure 1.

Additional samples of the glasses under investigation were wrapped in black paper, used in protecting photographic plates, and exposed to the source to determine the effect, if any, of heating (to 40 or $50^{\circ} \mathrm{C}$ ) as distinguished from the rejuvenation by heat treatment, which requires a temperature of $200^{\circ} \mathrm{C}$ or higher (10) (11) to be effective.

After finding that the maximum rejuvenation is caused by wave lengths in the region of $340 \mathrm{~m} \mu$ to $405 \mathrm{~m} \mu$, the investigation was continued with fewer filters and, for convenience, principally glass G584.

The samples of glass exposed under the filters were about $5 \mathrm{~cm}$ long, $1 \mathrm{~cm}$ wide, and $2.6 \mathrm{~mm}$ thick. The edges of the samples were painted with asphaltum varnish in order to prevent scattered radiation from entering the glass through the edge after passing around the filter. In this manner only radiation that had passed through the filter could enter the glass. 
While nearly all of the various makes of special window glasses were found to decrease in ultraviolet transmission on exposure to the sun, and to artificial sources of ultraviolet radiation (10), (and could be rejuvenated by the herein described methods), most of our observations were made on a sample of Vitaglass which was found to be especially photosensitive and which was available in a suitable thickness (about $2.6 \mathrm{~mm}$ ) and in a sufficient quantity at the time this investigation was undertaken.

\section{EXPERIMENTAL DATA}

Under this caption are given various data on solarization and rejuvenation of special window glasses that are transparent to short wave-length ultraviolet radiation. In the preliminary tests a phosphate glass (Corex A) and the following silicate glasses were under observation: Brephos, Helioglass, Sunlit, Uviol-Jena, and Vitaglass.

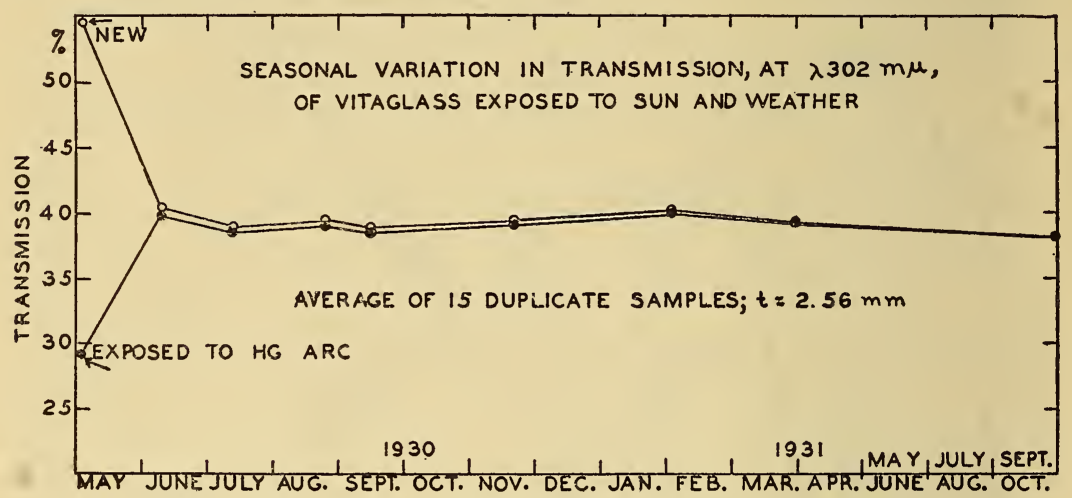

Figure 2.

Qualitatively the photochemical behavior of the various makes of silicate window glasses was found the same. Hence to simplify the presentation, a description is given of our observations only on Vitaglass, which has been on the market the longest and has thus afforded an opportunity for the most complete photochemical study.

\section{SEASONAL VARIATION IN TRANSMISSION OF SPECIAL WINDOW GLASSES}

Supplementing the earlier observations on various makes of glass (4) (5) in figure 2 is shown the seasonal variation in the ultraviolet transmission (at $302 \mathrm{~m} \mu$ ) of Vitaglass exposed to the sun and weather for about 2 years.

Fifteen pairs of samples of this kind of window glass $(2.5$ by $5 \mathrm{~cm}$ ) were used for this test. One sample of each pair was exposed to the quartz mercury arc for 10 hours (10). After this, the 30 samples were mounted in a frame (similar to a window frame) inclined at an angle of 45 degrees, facing south on the roof of a building, ${ }^{4}$ and exposed continuously day and night.

1 All exposures to solar radiation reported in this paper were made at the National Bureau of Standards, Washington, D. C. 
After an exposure of about 6 weeks (May 1 to June 10, 1930) the average transmissions of both sets of samples had become practically stabilized at about 40 percent, decreasing to 37 percent by September. (See fig. 2.)

During the winter months, owing to the low intensity or perhaps to the entire absence of the wave lengths shorter than about $300 \mathrm{~m} \mu$, there is a slight rejuvenation (amounting to about 1 percent) in transmission. However, this increase in transmission is so small that the average of a large number of samples is required to demonstrate the fact. Incidentally it is to be noted that this glass showed no appreciable surface weathering, the slight decrease in transmission during the second year no doubt being the completion of stabilization.

At the time of the writing of this paper most of the above-mentioned glasses had been exposed out of doors continuously for over 4 years, and the results show that after stabilization by exposure to the summer sun for about 3 months, the transmission remains practically constant, at a value which, for the most unstable glass, is only some 15 to 20 percent below the unstabilized transmission which obtains in the freshly made glass. This refutes rumors, circulated early in the production of these glasses, that they lose their ultraviolet transparency entirely after being in use for a short time.

\section{EFFECT OF HETEROGENEOUS ULTRAVIOLET RADIATION UPON THE TRANSMISSION OF GLASS}

The various data obtained relative to the effect of filtered and unfiltered heterogeneous radiation upon the ultraviolet transmission of (Vitaglass) window glass are described under three main captions ("Series"), depending upon the experimental procedure.

\section{(a) SERIES I}

In order to eliminate the additional effect of weathering, if any, during the study of the photochemical reaction as a function of the wave length of the exciting radiation, in the first experiments a group of glasses were exposed only when the sun shone and at all other times kept in the laboratory.

The exposures were made at approximately normal incidence. To accomplish this the glasses, with their ends resting on slats, were securely mounted upon (but separated from) a suitably inclined board which was placed upon a window sill and kept adjusted approximately normal to the sun's rays during the exposures.

After solarization by exposure to the total radiation from the quartz mercury arc for 10 hours, the glasses were mounted, as described above, and covered with filters of black paper, black celluloid (transparent to the infrared rays), or various glasses (either singly or in combination). The spectral transmissions of these filters are illustrated in figure 1.

In figure 3 are shown the results obtained with five samples of Vitaglass AG-2A with the filters indicated. Eight samples were actually tested under the following filters: (black paper; black celluloid; red glass; orange glass, G34; yellow Noviol B; light blue-green, G124J, plus Noviol B; purple, G986; and a deep blue-green, G584), but to avoid confusion in the illustration, the results obtained with three of the filters are not shown. 
As shown in figure 3, an exposure of 140 hours to winter sunlight (from November 9, 1929 to January 14,1930$)^{5}$ filtered through G584 increased the transmission of this sample from 18 to 29 percent. The results for the other samples during this initial period are not illustrated.

All of the samples were again exposed to the unfiltered mercury arc for 5 hours and then a new series of exposures to the sun was begun $(1: 14: 30)$.

It is to be noted, as shown in figure 3, that the samples under black paper and red glass respectively increased but little in transmission. The same was true of the sample exposed under black celluloid.

The transmission of the sample under the orange-colored filter, G34 (not illustrated in fig. 3) increased in transmission from 18.5 to only 23.5 percent in 400 hours, showing that radiation in the yellow, red, and infrared had but little rejuvenating effect.

The samples under Noviol B and under Noviol B plus G124J increased from 18.5- to 25-percent transmission, but there was in these cases some uncertainty about the effect of unfiltered light getting around the filters.

At first (1:14:30 to $4: 19: 30)$ the sample that was not covered with a filter underwent the greatest rejuvenation; next, the sample that was covered with the ultraviolet transmitting glass G986; then both decreased in transmission to 25.5-percent transmission at the expiration of 590 hours exposure. On the other hand, the sample under filter G584 increased in transmission to 29.5 percent (at $6: 26: 30$ ). The latter sample was then reduced in transmission (to 26.5 percent) by exposure directly to the sun for 2 days, after which a further exposure of 300 hours $(9: 26: 30)$ under G584 increased the transmission to 30.4 percent.

It is of interest to note, however, that in the period $1: 14: 30$ to $6: 26: 30$ the sample of Vitaglass exposed under the filter G584, which is opaque to radiation of wave lengths shorter than about $330 \mathrm{~m} \mu$, underwent a greater recovery in transmission than a duplicate sample exposed under G986 which is transparent to wave lengths shorter than $330 \mathrm{~m} \mu$. As will be shown presently, these short wave lengths produce stabilization at a lower transmission level.

At this stage of the observations an exposure of 10 days to direct autumn sunshine $(9: 26$ to $10: 7: 30)$ produced less solarization than 2 days in summer $(6: 26: 30)$.

These samples were then placed upon a deep ledge facing south (shielded from the rain) and exposed continuously, under the filters, without adjustment for normal incidence to the sun. During the winter months the transmission of the sample under the filter G584 did not increase above 29.2 percent, and direct exposure to the sun (no filters) for 10 days (1:20 to 1:30:31) produced but little solarization, indicating a close balance in the so called "antagonistic" action of the ultraviolet, when radiation of wave lengths 290 to $305 \mathrm{~m} \mu$ is very weak or entirely absent.

In this locality there is a rapid increase in the ultraviolet intensity in February (17). This is shown by the relatively rapid recovery in transmission (to 30 percent) of this sample of glass on exposure to the sun under the filter G584, for 11 days $(2: 11: 31)$; and by the subsequent increase in transmission to 31.2 percent in June 1931, when this series of observations was discontinued.

' In the text and illustrations such specific dates are, in most cases, abbreviated thus: 11:9:29 to 1:14:30. 
From the results obtained with these filters, particularly with the filters G584 and G986, it was concluded that the wave lengths most active in causing an appreciation in transmission are situated between $330 \mathrm{~m} \mu$ and $405 \mathrm{~m} \mu$.

\section{(b) SERIES II}

Although in the foregoing experiments the samples that were wrapped in black paper showed little or no change in transmission as a result of warming on exposure to solar radiation, it was desirable to make further observations concerning this question.

Instead of using slats on a board to support the glasses, a thin, lighttight wooden box (length $35 \mathrm{~cm}$; width $10 \mathrm{~cm}$; inside depth $5 \mathrm{~cm}$ ) was provided. The outside of this box was painted with aluminum; and the inside was painted black. Ventilation was obtained through openings in the back of the box, covered with baffles painted black, and so arranged that light could not enter the enclosure.

The top of the box (5 mm in thickness) contained holes over which were placed the filters on the outside, and the samples of Vitaglass on

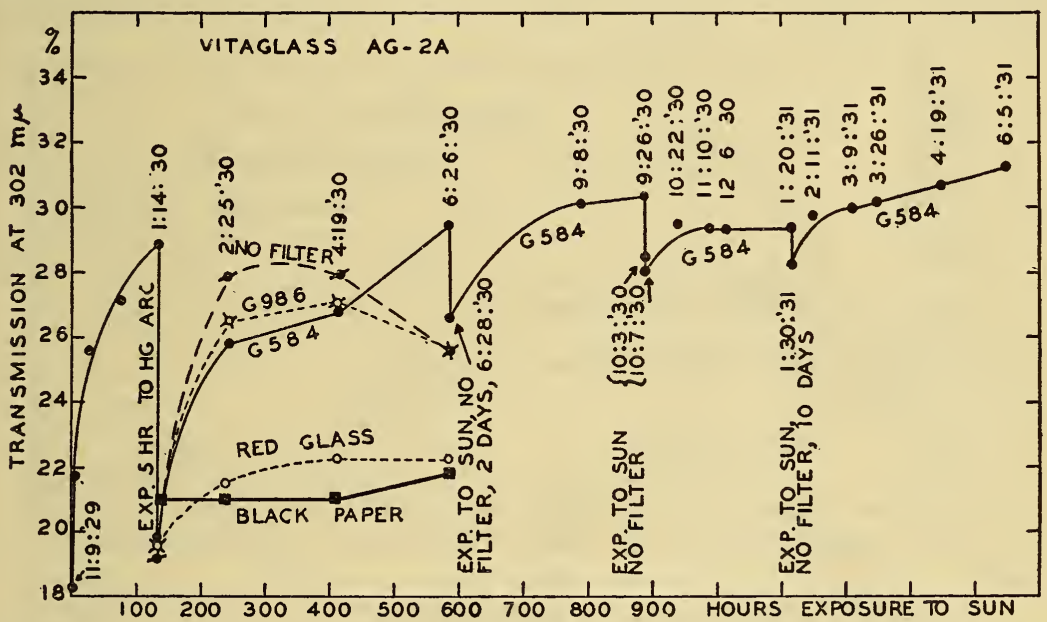

FIGURE 3.-Variation in spectral transmission of a sample of Vitaglass, using filtered and unfiltered solar radiation.

Exposures for first 900 hours made only when sun shone.

the inside. One sample, wrapped in black paper, was placed in the box near the samples exposed to the sun. To shield the samples of glass from dust, rain, and moisture, the edges of the filters were attached to the top of the box by means of Chatterton wax.

The filters used in this experiment were Corning glass G584, a piece of ordinary window glass (fig. 1), and a polished plate of crystalline quartz (7). The latter was used to shield the sample from the wind and weather, and to provide temperature conditions closely similar to the other samples, without shutting out the ultraviolet rays.

Another variation from series I was the "solarization" of the glass by the sun, instead of the quartz mercury arc lamp, before exposure under the filters.

In this rejuvenation test the box containing the samples was mounted on the roof of a building. The samples, in the box, facing 
south at an angle of $45^{\circ}$ to the vertical, were exposed continuously without adjustment to normal incidence to solar radiation.

Before beginning this series of rejuvenation tests the samples of Vitaglass under investigation were partially solarized by exposure directly to the sun for 10 days (June 6 to 16,1931 ), and at the expiration of this time the transmissions were as indicated in figure 4 . Beginning June 17 and continuing until October, the samples were continuously exposed under the filters.

The sample kept in the dark showed practically no recovery in transmission (at $302 \mathrm{~m} \mu$ ) during this experiment, which was continued to October 5, 1931.

The sample exposed under quartz continued to decrease in transmission until October when it was completely stabilized, as is shown by the subsequent exposure (no covering) through November 1932.

The sample under window glass became stabilized in transmission by July 12 , or about 3 weeks in advance of the sample exposed under Corning G584 (fig. 4). Part of this delay in attaining equilibrium under the filter, G584, is due to the much lower intensity of the radiation at $365 \mathrm{~m} \mu$. On the other hand, as will be shown presently,

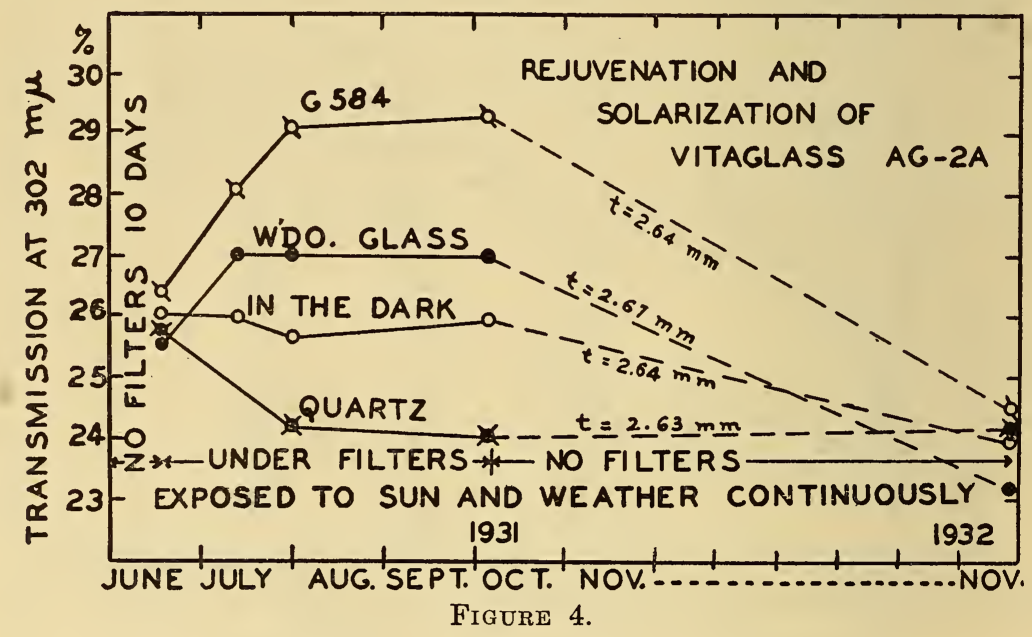

the shorter wave lengths, transmitted by the filter of window glass, have the property of stabilizing the transmission at a much lower value than the longer wave lengths, at 365 to $405 \mathrm{~m} \mu$. Hence the equilibrium level in transmission, resulting from exposure under window glass, should be lower than that attained under the filter of G584 glass.

解The sample under the filter G584 shows the greatest rejuvenation (by the wave lengths longer than about $330 \mathrm{~m} \mu$, as shown by fig. 1), the stabilization being practically complete by July 30 , 1931, with but little increase in transmission by October 5, 1931, when the filter exposures were terminated. This effect of wave length upon the equilibrium level in transmission (photochemical action) is more clearly demonstrated by using homogeneous radiation, as described on a subsequent page.

These glasses were then mounted in the frames, regularly employed in studying solarization, and exposed directly to the sun and weather 
continuously for a year. By the end of November 1932 the transmissions (at $302 \mathrm{~m} \mu$ ) were all reduced to the equivalent of about 24 percent (fig. 4) for a thickness of $2.64 \mathrm{~mm}$. The transmission in this case is considerably lower then the average of the 15 samples shown in figure 2. This is probably owing to the fact that this particular lot of samples was from an early melt. It was found to be unusually photosensitive, and hence because of this sensitivity was chosen for investigation of the selective action of different wave lengths in changing the ultraviolet transmission.

This series of observations confirmed the earlier measurements in showing that the maximum rejuvenation in transmission (aside from that resulting from heat treatment) is produced by ultraviolet radiation of wave lengths in the region of 310 to $405 \mathrm{~m} \mu$.

(c) SERIES III

A further test of rejuvenation by wave lengths in the region of 450 $\mathrm{m} \mu$ was made on two samples of Vitaglass which were first depreciated in transmission by exposure for 10 hours to the unfiltered radiation from the quartz mercury arc. The one sample was then exposed for 115 hours to the filtered radiation, principally of wave lengths $436 \mathrm{~m} \mu$ and $546 \mathrm{~m} \mu$ from the quartz mercury arc, isolated by means of a combination filter (of Noviol A and G584 glasses; fig. 1) which had a transmission of about 45 percent at $436 \mathrm{~m} \mu$.

To test the effect of the temperature alone the second sample, wrapped in black paper, was mounted adjacent to the sample under the glass filters, and similarly exposed to the lamp.

The results of this test verify the earlier observations, using filtered sunlight, showing an increase (see fig. 3 , red glass) in transmission (at $302 \mathrm{~m} \mu$ ) as a result of exposure to filtered radiation of wave lengths longer than $405 \mathrm{~m} \mu$. In this test the increase amounted to 2 percent as compared with an increase of about 1 percent in transmission of the sample wrapped in black paper.

Apparently the wave lengths longer than $405 \mathrm{~m} \mu$, have a slight effect in rejuvenation; but this is not comparable with the highly selective action of the wave lengths in the region of $365 \mathrm{~m} \mu$. Since colorless glass has but little absorption in the region of $405 \mathrm{~m} \mu$ only slight, if any, photochemical action by radiation of this wave length is to be expected.

\section{EFFECT OF HOMOGENEOUS ULTRAVIOLET RADIATION UPON THE TRANSMISSION OF GLASS}

The completion of an investigation of the physiological (erythemal) action of homogeneous ultraviolet radiation (14) released apparatus for a similar study of the photochemical action of these wave lengths upon the ultraviolet transmission of glass. The results of this study, using the experimental procedure described under caption II, are given in this subhead.

In a previous paper (10) it was shown that exposure to heterogeneous ultraviolet radiation changes (degrades or increases) the transmission throughout the whole ultraviolet spectrum investigated (250 to $400 \mathrm{~m} \mu$ ). Hence it was of interest to determine the effect of exposure to homogeneous radiation of a single wave length upon the ultraviolet spectral transmission. As shown in figure 5, the effect of exposure to homogeneous radiation, of different wave lengths, is to produce a 
series of spectral transmission curves which are similar in outline but different in the magnitude of the transmission, depending upon the effectiveness of the different wave lengths in producing a stabilized photochemical change in the glass, the shortest wave lengths being the most effective. While this was no doubt to be expected, nevertheless, in view of the novelty of some of the herein recorded observations, it was desirable to verify our procedure of using the transmission for radiation of a single wave length, at $302 \mathrm{~m} \mu$, as a criterion for judging the photochemical change in glass (as described in caption II) which is exhibited as a change in transmission throughout a wide band of the ultraviolet spectrum.

In this connection it is relevant to add that the use of the emission line at $302 \mathrm{~m} \mu$ as a means for studying photochemical change in glass, in which the substances undergoing a chemical change have wide over-

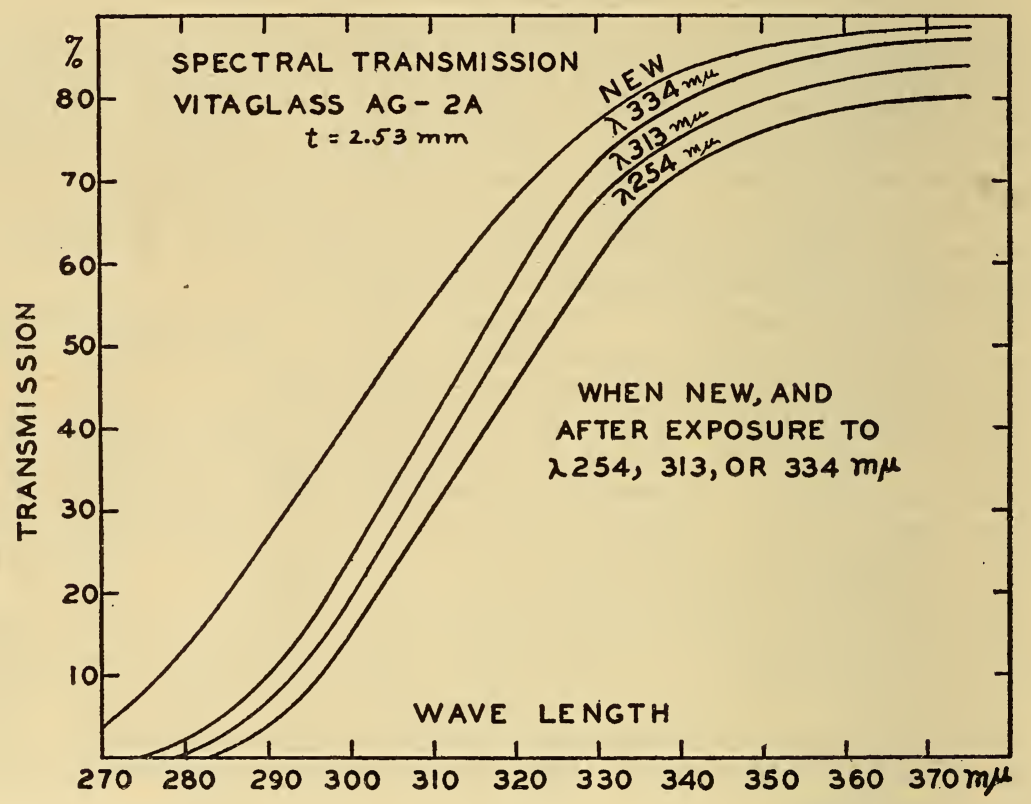

FIGURE 5.-Effect of exposure to homogeneous radiation of different wave lengths upon the ultraviolet transmission of Vitaglass (a soda-lime-silica glass).

lapping bands of absorption throughout the ultraviolet, is not to be construed as generally applicable, particularly in the study of substances having narrow bands of selective absorption (16).

\section{(a) EFFECT UPON A SODA-LIME-SILICA GLASS}

At the beginning of the observations the sample of Vitaglass (a sodalime-silica glass containing iron oxide as an impurity) under examination had a transmission at $302 \mathrm{~m} \mu$ of about 26 percent when completely solarized in sea level summer sunlight, figure 6 . The transmission was further degraded, to about 21 percent, by exposure to the unfiltered radiation from the quartz mercury arc. The glass was then kept wrapped in black paper at room temperature several weeks before beginning the following series of observations using homogeneous radiation of measured intensities (microwatts per $\mathrm{cm}^{2}$ ). 
The result of the sequence of exposures to different wave lengths is illustrated in figure 6 , in which the ordinates are percent transmissions at wave length $302 \mathrm{~m} \mu$ and the abscissas are in billions $\left(10^{9}\right)$ of

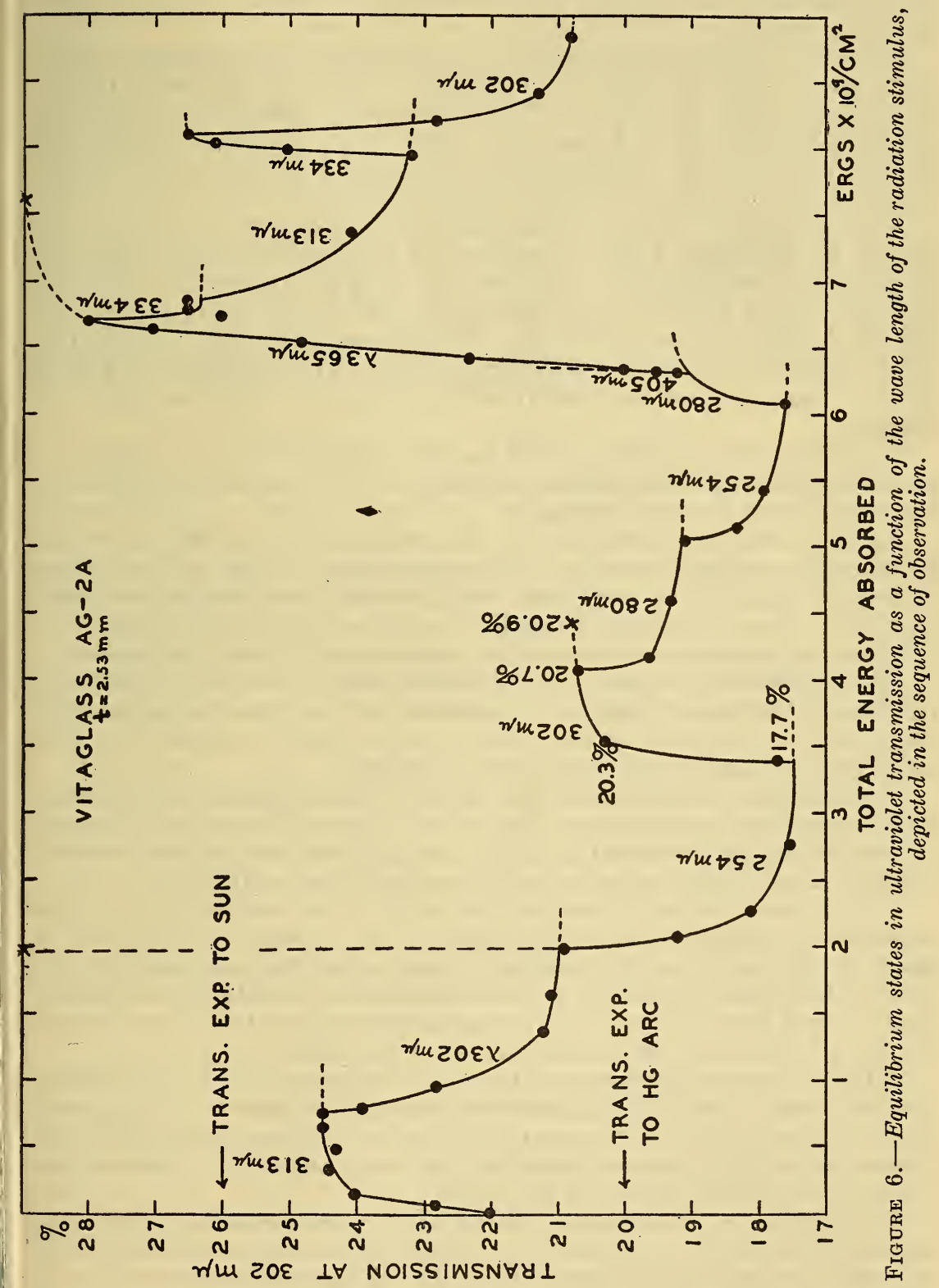

ergs of the energy absorbed in the glass per $\mathrm{cm}^{2}$ of the irradiated surface. These values are obtained from the intensity of the incident radiation and the average absorption during the interval of irradiation between two successive sets of transmission measurements. 
The first exposure to homogeneous radiation of wave length $313 \mathrm{~m} \mu$ increased the transmission from 21 to 24.5 percent. This is illustrated in figure 6 in which the dotted extensions of the curves are extrapolations showing how nearly the photochemical action appears to be completed.

The second exposure was made to wave length $302 \mathrm{~m} \mu$ which reduced the transmission to about 20.9 percent. This was followed by an exposure to radiation of wave length $254 \mathrm{~m} \mu$ which further reduced the transmission to 17.6 percent. After this, another exposure to $302 \mathrm{~m} \mu$ restored the transmission to practically the value previously obtained with this wave length, at equilibrium.

At this stage of the experiment the transmission was again depreciated, in two steps, first by exposure to the emission line at $280 \mathrm{~m} \mu$ (equilibrium transmission 19.2 percent), then by exposure to the line $254 \mathrm{~m} \mu$, which reduced the transmission to 17.6 percent previously obtained with this wave length. This shows that the shorter the wave length the lower the equilibrium level in transmission and that this is determined independently of the exposure to intervening wave lengths.

Following the exposure to $254 \mathrm{~m} \mu$ the transmission was again restored to its previous equilibrium level, at 19.2 percent, by exposure to the emission line at $280 \mathrm{~m} \mu$.

An exposure was then made to the emission line at $405 \mathrm{~m} \mu$ which has a relatively high intensity. However, owing to the small amount of energy absorbed by the glass, the photochemical change produced was slow, about 2 weeks of irradiation being required to obtain the 0.8 percent increase in transmission, as indicated in the illustration.

An exposure then made to the emission line of wave length $365 \mathrm{~m} \mu$ increased the transmission to 28 percent, with a possible increase to 29 percent as observed on a duplicate sample used in another test and indicated by the dotted extension in figure 6 .

The exposure to the line at $365 \mathrm{~m} \mu$ was followed by a depreciation in transmission by exposure to the emission line at $334 \mathrm{~m} \mu$ (equilibrium transmission, 26.5 percent), and a further decrease in transmission (to 23.2 percent) by exposure to the emission line at $313 \mathrm{~m} \mu$.

It is relevant to note that at this stage in the irradiation test the equilibrium transmission (23.2 percent) for exposure to $313 \mathrm{~m} \mu$ is lower than the value (24.5 percent) observed at the beginning of the observations after exposing to the emission line at $313 \mathrm{~m} \mu$. Inspection showed that this decrease in transmission was not to be accounted for by a visible change in the surface of the glass.

After this second exposure to the emission line at $313 \mathrm{~m} \mu$ the transmission was increased by exposure to the emission line at $334 \mathrm{~m} \mu$, and again depreciated by exposure to the line at $302 \mathrm{~m} \mu$, the equilibrium transmission (20.8 percent) reaching the same value (20.9 percent) as observed at the beginning of the series.

In addition to the tests on Vitaglass (a soda-lime-silica glass containing iron oxide as an impurity), observations were made also on a sample of iron-free soda-lime-silica glass (thickness $=2.96 \mathrm{~mm}){ }^{6}$

The transmission at $302 \mathrm{~m} \mu$ before exposure was 57 percent. After depreciation by exposure to the unfiltered radiation from the quartz

${ }^{6}$ Prepared by F, C. Flint of the Hazel Atlas Glass Co. 
mercury arc the transmission was 40 percent. Further exposure to the quartz mercury arc under the filter G584 increased the transmission to 47 percent. Exposure then to homogeneous radiation of wave length $313 \mathrm{~m} \mu$ for 35 hours decreased the transmission to 42.8 percent, showing that the pure soda-lime-silica glass as well as the impure glass has levels of photochemical stabilization which vary with the wave length of the activating radiation.

Evidently the observed photochemical action is in the pure sodalime-silica portion of the glasses and not in the iron oxide impurities. There is no doubt but that the presence of the iron oxide lowers the transmission throughout the ultraviolet; but, comparing the results obtained on the iron-free glass with those on the glass known to contain iron, it does not appear that the iron oxide increases the photochemical action that occurs in the pure soda-lime-silica glass. If the iron oxide itself undergoes a photochemical change, as is commonly accepted, the products formed do not appear to produce a change in the ultraviolet transmission comparable to that observed in the relatively iron-free soda-lime-silica glass (23).

\section{(b) EFFECT UPON A PHOSPHATE-LIME GLASS}

A difficulty in studying the photochemical stability of ferrous and ferric iron in a soda-lime-silica glass arises from the fact that the ultraviolet absorption of the glass and of the iron oxide occurs in a wide spectral band, beginning at about $350 \mathrm{~m} \mu$ and extending to an unknown wave length shorter than $280 \mathrm{~m} \mu$.

It is therefore of interest to include some observations on the change in transmission of Corex-A glass which is known to contain a small amount of iron oxide as an impurity, but which, in the unsolarized condition, has a high transmission throughout the region of 250 to $320 \mathrm{~m} \mu(10)$.

Radiation of wave lengths 295 to $313 \mathrm{~m} \mu$ from the sun does not affect the ultraviolet transmission, but shorter wave lengths, from a quartz mercury arc, produce a marked decrease in ultraviolet transmission in the region of 250 to $365 \mathrm{~m} \mu$, the resulting transmission curve having some resemblance to that of the soda-lime-silica glass (10).

The main constituent of Corex-A Glass is fused calcium phosphate, with the oxides of $\mathrm{Al}, \mathrm{B}, \mathrm{Mg}, \mathrm{Na}, \mathrm{Si}$, and $\mathrm{Fe}$ as minor constituents (13). The iron oxide content reported by Starkie and Turner (13) is of the order of 0.03 percent.

In the present work the ultraviolet spectral transmission of an optically polished sample of Corex-A glass, $3.67 \mathrm{~mm}$ in thickness, (see fig. 7), new, and after exposures of 17 and 34 hours, was depreciated by exposure to the unfiltered radiation of a high potential mercury vapor arc ${ }^{7}$ discharge in which the ultraviolet radiation of wave lengths shorter than $313 \mathrm{~m} \mu$ is confined almost entirely (95 percent) to the resonance emission line at $253.7 \mathrm{~m} \mu$. After being kept in the dark for 12 days, during which the transmission at $302 \mathrm{~m} \mu$ increased a small amount (from 21.5 to 22.2 percent), the glass was exposed for 22 hours to homogeneous radiation of wave length $313 \mathrm{~m} \mu$, with no appreciable change in transmission.

The glass was then exposed for 48 hours to the emission line at 365 $\mathrm{m} \mu$ without producing a measurable change in transmission. This

7 The "Sc-2537 tube", made by the Research Lab., Hanovia Chemical and Manufacturing Co. 
is remarkable in view of the fact that a similar exposure of Vitaglass (a soda-lime-silica glass) for the same length of time would have raised the transmission about 9 percent, or to practically the equilibrium level (29 percent), indicated in figure 6.

As already noted, Corex-A (a phosphate) glass is interesting because the main constituents have little or no absorption in the region of 280 to $350 \mathrm{~m} \mu$ in which the photosensitive substance undergoes a photochemical change. After depreciating the transmission by radiation of wave length $254 \mathrm{~m} \mu$ it has not been possible to reverse the photochemical action by means of the wave lengths at 302 to $365 \mathrm{~m} \mu$. It would be interesting to determine whether the wave length at $254 \mathrm{~m} \mu$ reverses the action of the emission lines at $200 \mathrm{~m} \mu$ and shorter wave lengths (easily obtainable by using the spark

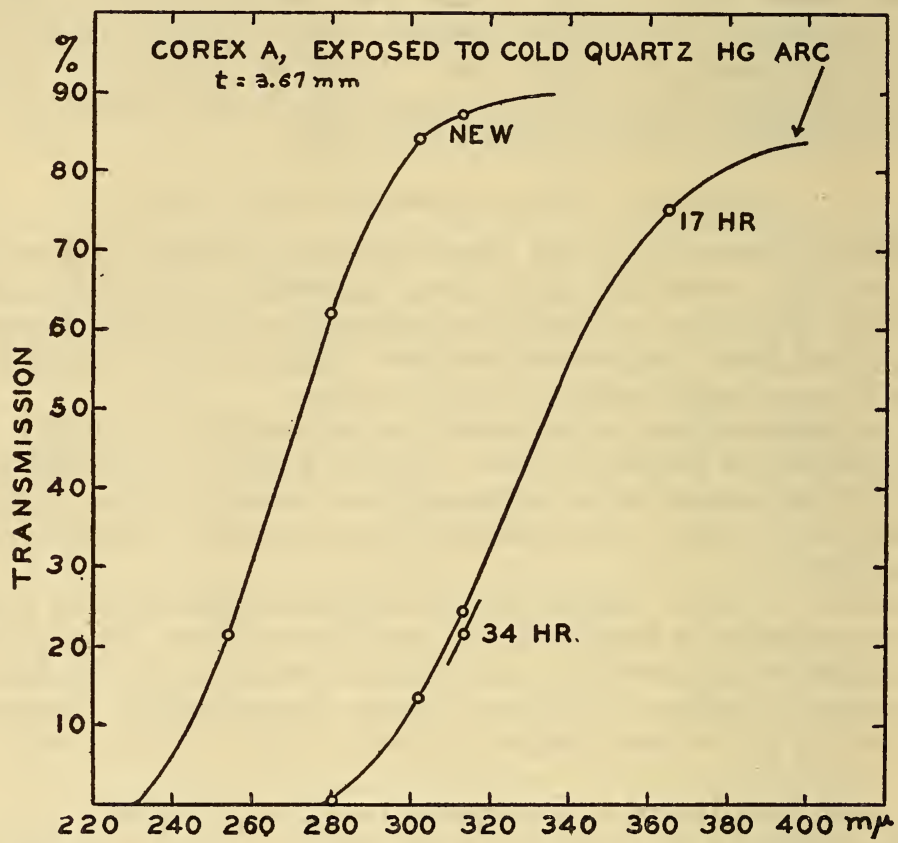

FIGURE 7.-Effect of exposure of Corex $A$ (a phosphate glass) to radiation, chiefly of wave length $253.7 \mathrm{~m} \mu$.

discharge between electrodes of $\mathrm{Zn}$ and of $\mathrm{Al}$ ); but to determine the transmission at these short wave lengths it would be necessary to use very thin samples of glass.

\section{SPONTANEOUS RECOVERY IN TRANSMISSION}

It was of interest to determine the change in transmission of the irradiated as compared with the unirradiated portion of a sample of glass kept in the dark at laboratory temperature after a 10-hour exposure of a small area to the unfiltered radiation from a quartz mercury arc. For this purpose the central portion (suitably marked), $2 \mathrm{~mm}$ wide and $15 \mathrm{~mm}$ long, of a sample of Vitaglass was irradiated and the transmission measured by moving the exposed and the adjacent unexposed area laterally across the spectrometer slit, which was $0.6 \mathrm{~mm}$ in width. The wave length $313 \mathrm{~m} \mu$ was used in the 
transmission measurements because of the higher intensity, which increased the accuracy, and with fewer observations shortened the time of exposure necessary for making the measurements.

As shown in figure 8, the difference in transmission at wave length $313 \mathrm{~m} \mu$ between the unexposed and the freshly exposed portion was $(50.5-36: 5=) 14.0$ percent. After being kept in the dark for 2, 7 , and 12 months the difference in transmission was found to have decreased respectively to $11,8.5$, and 9 percent.

During an interval of 7 months' storage after exposure (at laboratory temperature) there is a spontaneous recovery of about 4.5 percent (36.5 to 41.0 at $313 \mathrm{~m} \mu$ ) in the transmission of the exposed part. During the comparatively short time required for the transmission measurements, the sample was exposed to the unfiltered radiation of the mercury arc, and the solarization resulting from this on the

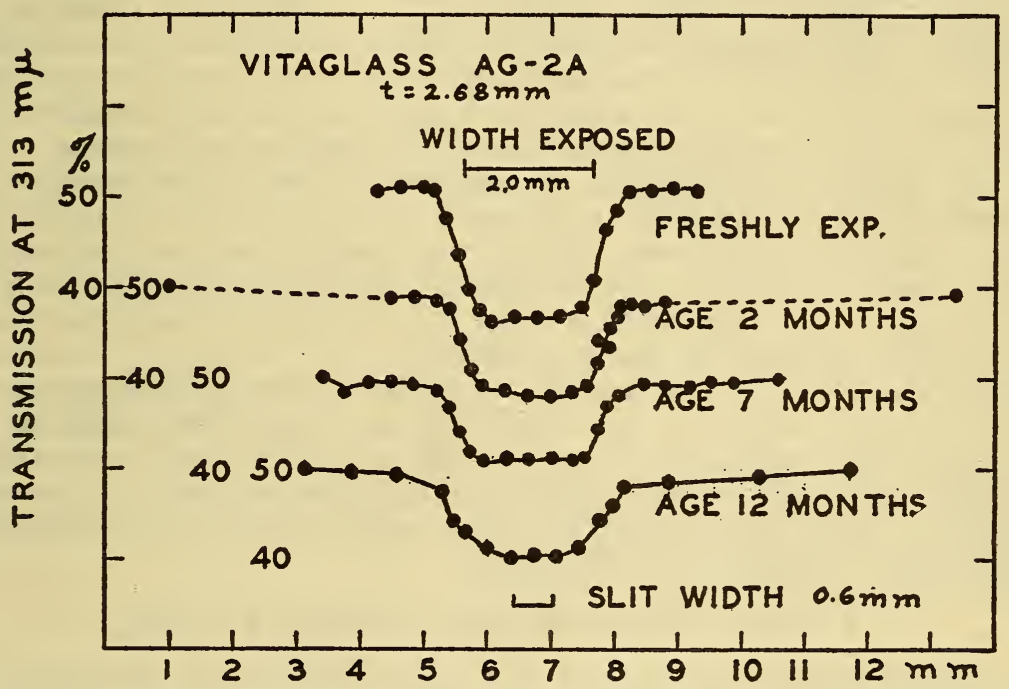

FIGURE 8.-Spontaneous recovery in transmission of a sample of Vitaglass depreciated by exposure to ultraviolet radiation, then kept in the dark, at room temperature.

"exposed" part is unquestionably negligible. Whether the 1 percent lower transmission of the unexposed part is owing to depreciation during observations is unknown.

The spontaneous recovery in transmission of this sample no doubt explains part of the observed increase in transmission of the sample exposed to the sun under red glass (fig. 3) which after exposure to the lamp and before exposure under the glass had practically the same transmission as this sample (18 to 19 percent) at $302 \mathrm{~m} \mu$. On the other hand, the sample (fig. 4) from the same plate which had not been so strongly irradiated (transmission reduced to 26 percent at $302 \mathrm{~m} \mu$ ) changed but little in transmission during the 3 months' storage after exposure, which is probably to be expected.

The spontaneous recovery of a substance that has undergone a photochemical change by exposure to ultraviolet radiation has become a well-known phenomenon. The object of the present observations was to inquire into this question relative to glass, which, being 
a solid solution, shows no appreciable widening of the area of photochemical action by diffusion out from the region exposed. This is well illustrated in the lower part of figure 8, "age 12 months."

The spontaneous recovery in transmission (fig. 8) amounting to about 4.5 percent at $313 \mathrm{~m} \mu$ in 7 months corresponds to about 4.0 percent (actual transmission 18 to 22 percent) at $302 \mathrm{~m} \mu$. From this it may be seen that the spontaneous recovery in transmission (amounting to 0.5 percent per month) during the irradiation, as in figure 6 , is small and is overshadowed when the glass is exposed to wave lengths which depreciate the transmission

\section{DISCUSSION OF DATA}

In the absence of a chemical analysis of the small quantities of the products formed in glass by exposure to ultraviolet radiation of different wave lengths, recourse is had to a physical (spectroradiometric) analysis of the absorption spectrum, which is a characteristic of every substance and, hence, a change in this is indicative of a change in the chemical composition of the glass by irradiation.

The present investigation is confined to the absorption in the extreme ultraviolet which undergoes a marked change on irradiation of the glass. In contrast, the infrared absorption spectrum of the glass changes but little, on irradiation; and this change is confined principally to the region of $1 \mu$ where there is a weak absorption band, commonly ascribed to ferrous oxide.

Incidentally, it is relevant to note that as the glass decreases in transparency, owing to the action of the ultraviolet radiation in changing the iron oxide from the ferrous to the ferric condition, the glass increases in transparency to the infrared (at $1 \mu$ ); but this change is very small relative to the large change in transmission observed in the extreme ultraviolet.

\section{PHOTOCHEMICAL EQUILIBRIUM STATES}

As noted in the beginning of this paper the variation in ultraviolet transmission is an indication of the magnitude of the photochemical change produced in a glass on exposure to ultraviolet radiation of certain wave lengths. After exposure to radiation of a given wave length for a sufficient length of time, there is no further change in transmission, indicating that an approximate photochemical equilibrium is established.

\section{(a) A SODA-LIME-SILICA GLASS}

As shown in figure 6 , for each wave length of the exciting radiation there is an equilibrium value in the transmission (i.e., of the photechemical action), the direction of the change in transmission to attain this equilibrium level depending upon the existing condition or state of the glass. The shorter the wave length (between 254 and $365 \mathrm{~m} \mu$ ) of the homogeneous exciting radiation, the lower the equilibrium value of the transmission.

If the ultraviolet transmission is below the equilibrium value, as a result of previous exposure to wave lengths shorter than the one under consideration, prolonged exposure to this wave length increases the transmission to the equilibrium value. On the other hand, if by heat treatment or by exposure to wave iengths longer than the 
one under consideration, the transmission is raised above the equilibrium value for this wave length, then exposure to this wave length decreases the transmission to the equilibrium value (19). In other words, for each wave length, the photochemical reaction in an ordinary soda-lime-silica glass is reversible, the direction of the reaction depending upon the existing condition or state of the glass.

By extrapolation of the various curves of appreciation and depreciation in transmission, as indicated by the dotted parts of the curves depicted in figure 6 , it is possible to obtain the approximate equilibrium value of the transmission for each wave length of the exciting radiation used, and to obtain an indication of the relative magnitude of the photochemical change involved in passing from one of the corresponding photochemical equilibrium states to any one of the others.

As shown in figure 9 the transmission equilibrium (thickness of glass $2.53 \mathrm{~mm}$ ) rises from about 17.5 percent for wavelength $254 \mathrm{~m} \mu$ to about 29 percent for wave-length $365 \mathrm{~m} \mu$. The higher of the two points at $313 \mathrm{~m} \mu$ was obtained in the first part of the cycle of exposures, and apparently does not belong with the other data. As already mentioned, the glass appears to have undergone a permanent change in transmission-a question that will require further investigation.

One sample which had been subjected to heat treatment at $500^{\circ} \mathrm{C}$ and subsequently exposed to wavelength 365 $\mathrm{m} \mu$ (also a duplicate sample exposed under a filter opaque to practically all radiation

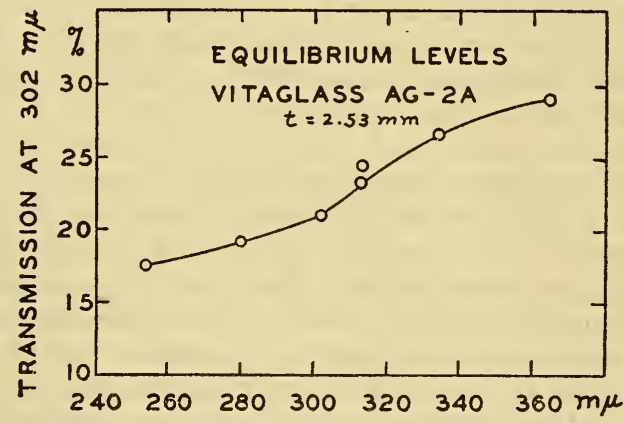

Figure 9.-Equilibrium states in ultraviolet transmission after exposure to homogeneous radiation of different wave lengths. (See fig. 6.) shorter than $365 \mathrm{~m} \mu$ ) decreased several percent in transmission upon 100 hours continued exposure. The decrease in transmission was rather slow, but the data indicated the possibility of either a small permanent change in the glass or else an equilibrium level slightly above 29 percent.

The logical procedure would have been to make a thorough examination of photochemical equilibrium states in a soda-lime-silica glass that is as free as possible from contamination with iron oxide. However, the first step was to establish the reality of the photochemical equilibrium levels. After this, the filter method can replace the slow process of stabilization by isolated spectral lines. In this manner (as already mentioned), by using filters it has been established that this photochemical reaction occurs in the purest iron-free samples of soda-lime-silica glass yet examined. The evidence at present available indicates that this remarkable photochemical change occurs in the soda-lime constituent and that the change, if any, in the iron oxide is an additional reaction (23).

In this connection, it is relevant to record transmission tests on samples of bottle glass (a soda-lime-silica glass, decolorized with manganese) that were colored a deep amethyst, as a result of exposure 
to the sun. An additional exposure to the unfiltered, short wave length radiation from the quartz mercury arc decreased but little the ultraviolet transmission (10). On exposure of this sample to filtered radiation (principally of wave length $365 \mathrm{~m} \mu$ ) from the quartz mercury arc lamp, the ultraviolet transmission was appreciably increased. This is in agreement with the observations on the sodalime-silica glasses that had not been decolorized.

\section{(b) A PHOSPHATE-LIME GLASS}

In contrast with soda-lime-silica glasses, which, even in their purest state, show an appreciable absorption at $350 \mathrm{~m} \mu$, and which, in thicknesses of $2 \mathrm{~mm}$, are practically opaque to radiation of wave lengths shorter than $280 \mathrm{~m} \mu$, Corex A (a phosphate glass containing a small amount of iron oxide as an impurity or nonessential constituent) before irradiation, is highly transparent to radiation of wave lengths longer than $280 \mathrm{~m} \mu$. (See fig. 7.) Apparently the behavior of iron oxide in a phosphate glass is different from that observed in soda-lime-silica glass. (See fig. 5.)

After prolonged irradiation by wave lengths shorter than $280 \mathrm{~m} \mu$ the phosphate glass shows a reddish color, and the ultraviolet transmission is greatly decreased (fig. 7), but whether the absorbing substance, with its strong absorption at $365 \mathrm{~m} \mu$ and shorter wave lengths, is an oxide of iron (ferric oxide) remains to be determined.

The outstanding conclusions are that exposure of the previously irradiated phosphate glass to wave lengths (302 to $365 \mathrm{m \mu}$ ) which are highly absorbed by the glass after irradiation, does not restore the transparency as it does in the soda-lime-silica glass and that only heat treatment will (partially) restore the transmission (10) (11).

Because of the complicated nature of the results, this whole investigation is being continued, by using different combinations of materials in the glass, and by using filter methods to facilitate the photochemical tests.

\section{RELATION BETWEEN THE TRANSMISSION AND THE INTEGRATED ENERGY ABSORBED}

In figure 6 the abscissas represent the total radiant energy absorbed in the glass, no distinction being made between the amount absorbed by the main constituents of the glass ${ }^{8}$ and the amount absorbed by the photosensitive substance which undergoes the photochemical reaction (indicated by the change in transmission) because at this stage of knowledge of the subject, no distinction as to the amount absorbed by the different components seems justifiable.

The abscissas in figure 6 represent all the energy absorbed in the glass in changing from one equilibrium level to another. The curves serve the purpose of depicting our observations in a connected manner, but without further data they cannot be used to elucidate several important questions. For example, the rate of transition in going from one equilibrium level to another depends upon the starting point and cannot be determined directly from the data illustrated in figure 6.

The slopes of the transmission curves (e. g., for the $365 \mathrm{~m} \mu$ line and the $254 \mathrm{~m} \mu$ line) are not comparable, because one is at the initial

\footnotetext{
${ }^{8}$ Whether and to what extent the constituents $\mathrm{Na}_{2} \mathrm{O}$ and $\mathrm{CaO}$ are affected by ultraviolet radiation, and
} the role of iron oxide and free oxygen, remains undetermined (23). 
stage and the other is at the final stage of the reaction. The slope of the recovery curve using the $365 \mathrm{~m} \mu$ line appears steeper than the depreciation curve using the $254 \mathrm{~m} \mu$ line. However, if the latter curve had been observed beginning at the equilibrium level at 29 percent, as indicated by the dotted line in figure 6 , the slope of the initial part of this transmission curve might be just as steep as that of the $365 \mathrm{~m} \mu$ emission line at its initial stage (22).

Manifestly, as indicated in figure 6, the total energy required to attain equilibrium depends upon the history of the photosensitive material. From an inspection of the sections of the curves in figure 6 , it appears that the total energy absorbed in going from one equilibrium level to a lower equilibrium level is greater than that absorbed in returning to the original equilibrium level. Further investigation is required to determine whether this is generally true and whether it is owing to a difference in the heat of formation and heat of disassociation of the photosensitive substance.

In figure 5 the spectral transmission curves marked "new", and particularly the curve marked " $334 \mathrm{~m} \mu$ ", are typical of soda-limesilica window glasses, whether or not they contain a photosensitive substance that changes in transmission on exposure to ultraviolet radiation.

From these curves it can be seen that the main constituents of the glass are almost completely opaque to radiation of wave lengths 280 $\mathrm{m} \mu$ and shorter, whereas at wave lengths longer than $365 \mathrm{~m} \mu$ (to $405 \mathrm{~m} \mu$, not illustrated in fig. 5) only 2 to 3 percent of the incident radiation is absorbed by the glass. From this it can be seen that, for wave lengths $254 \mathrm{~m} \mu$ and shorter, the depth of penetration is shallow and that the greatest photochemical action occurs near the surface of the glass facing the incident radiation. On the other hand, for the wave lengths $365 \mathrm{~m} \mu$ and longer, the penetration is deep and, during the process of formation and disintegration of the photosensitive substance, the concentration is more uniform throughout the irradiated layer of glass.

In view of the foregoing considerations it is evidently desirable to obtain some idea of the energy relations involved directly in the photochemical reactions. Without a chemical analysis data are lacking regarding the concentration of the photosensitive substance. The only reference points are the equilibrium states where (as evidenced by the constant value of the transmission) no further chemical change is produced by a given wave length, and the energy absorbed is apparently converted into heat, just as occurs in any glass not containing a photosensitive material. Using these equilibrium levels as reference points, and using the changes in transmission as a measure of changes in concentration, calculations are in progress on the energies involved in the formation and disintegration of the photosensitive substance. We hope to be able to report further on this subject.

In concluding the discussion under this caption it is to be noted that contrary to earlier reports, in our examinations of samples of soda-lime-silica glass, prepared from materials practically free from iron oxide, a depreciation in transmission was observed. While the stabilized transmission at $302 \mathrm{~m} \mu$ was much higher than that of similar glasses containing a small amount of iron oxide, the percentage change in transmission on solarization was about the same for 
the two kinds of glass. This is in agreement with some of the earlier observations on various kinds of special window glasses (10). In this connection, it is relevant to note that Starkie and Turner (13) found that the ratio of the ferrous oxide to the total iron oxide was fairly uniform over a relatively wide range of concentrations of iron oxide in the glass.

As a final remark it is relevant to note that, in the spectral range investigated, the shortest and the longest wave lengths have the power to produce the greatest photochemical changes; the former in depreciating, the latter in appreciating the transmission of a sodalime-silica glass.

\section{REFERENCES AND NOTES}

1. BS Tech. News Bul. No. 126, p.4 (October 1927).

2. Wood and Leathwood, Nature (September 21, 1929).

3. BS Tech. News Bul. No. 152, p.116 (December 1929). Subsequent tests confirm the surmise of this early date that the greatest rejuvenation in transmission is produced by radiation in the spectral region of $365 \mathrm{~m} \mu$.

4. BS Tech. News Bul. No. 160, p.80 (August 1930). This overshooting in recovery in transmission was found in 17 out of 20 samples of different makes of glass.

5. BS Tech. News Bul. No. 164, p.118 (December 1930).

6. BS Tech. News Bul. No. 162, p.97 (October 1930).

7. BS Tech. News Bul. No. 174, p.109 (October 1931).

8. Stockbarger and Johnson, J. Frank. Inst. 210, 455 (October 1931).

9. See summary by Sheppard, Chem. Rev. 4, 319 (1927).

10. W. W. Coblentz and R. Stair, BS J. Research 3, 629 (1929) RP113. This paper gives data on ultraviolet solar radiation and the solarization of window materials.

11. A. Q. Tool and R. Stair, BS J. Research \%, 357 (1931) RP345. This paper gives data on the restoration of solarized ultraviolet transmitting glasses by heat treatment.

12. Strahlentherapie, 28, 125 (1931); 39, 452, 485, 490, and 798 (1931); and 40, 709 and 717 (1931).

13. Results of researches showing that ferric oxide in glass strongly absorbs the ultraviolet and has relatively smaller absorption in the infrared, in contrast with ferrous oxide which has a comparatively greater absorption in the infrared and smaller absorption in the ultraviolet were published by Crookes, Phil. Trans. Roy. Soc., 214A, 1 (1914), and more recently by Starkie and Turner, Trans. Soc. Glass Tech., 12, 306 and 324 (1928). The paper by Starkie and Turner cites numerous researches showing: that glass containing iron oxide in the ferrous state has a higher transmission in the short wave length ultraviolet than an equal content of ferric oxide; that the ferric oxide is dissociated by heat treatment (11); and that evidently in the preparation of most of the commercial ultraviolet glasses reducing conditions are employed.

14. W. W. Coblentz, R. Stair, and J. M. Hogue, BS J. Research 8, 541 (1932) RP433; W. W. Coblentz, R. Stair, and J. M. Hogue, BS J. Research 8, 759 (1932) $\mathrm{RP} 450$.

15. W. W. Coblentz, R. Stair, and J. M. Hogue, BS J. Research 7, 723 (1931) RP370. On page 738 is given a short description of the quartz-fluorite spectroradiometer, its spectral transmission, and its calibration in absolute value.

16. The simultaneous occurrence of two photochemical reactions, at different rates, when a substance (ergosterol) is exposed to heterogeneous ultraviolet radiation is recorded in the following papers:

Heilbron, Kamm, and Morton, Biochem. J. 21, 78 (1927).

Bills, Honeywell, and Cox, J. Bio. Chem. 80, 557 (1928).

Bourdillon, Fischmann, Jenkins, and Webster, Proc. Roy. Soc. 104B, 561 (1929).

Reerink \& Van Wijk, Biochem. J. 23, 1294 (1929).

Marshall and Knudson, J. Am. Chem. Soc. 52, 2304. (1930.) Homogeneous radiation was used.

17. W. W. Coblentz and R. Stair, BS J. Research 6, 951 (1931) RP318.

18. W. W. Coblentz and R. Stair, Techn.Pap.BS 22, 555 (1928) T369. (See page 558.) 
19. BS Tech. News Bul. No. 201, p.3 (January 1934). Further discussion of the solarization of glass.

20. Damon and Daniels, J. Am. Chem. Soc., 55, 2363 (1933). This paper gives a discussion of the influence of water on the photolysis of gaseous acetone.

21. S. Sugie, Repts. Imp. Ind. Research Inst., Osaka, 8, 1 (1927).

22. Porter and Iddings, J. Am. Chem. Soc., 48, 40 (1926), found the rate of decomposition of acetone into ethane and $\mathrm{CO}$ independent of the wave length in the region of 2200 to $3400 \mathrm{~A}$.

23. As stated on page 776, footnote 2 , samples of (relatively iron free) sodalime-silica and soda-silica glasses, prepared from pure materials, in a platinum crucible (heated in an electric furnace), exhibit stages of photochemical equilibrium, as observed in the window glasses. In contrast, a similarly prepared sample of potash-lime-silica glass, which in a thickness of $2.6 \mathrm{~mm}$ is highly transparent to the ultraviolet (transmission 16 percent at $254 \mathrm{~m} \mu$ ) was not appreciably affected by ultraviolet radiation. From the observations on these three kinds of glass it appears that soda is the photosensitive constituent in a soda-lime-silica glass.

Washington, D. C., May 15, 1934. 